\title{
Rotavirus-infected children with clinically mild encephalopathy with a reversible splenial lesion (MERS)
}

\author{
Tadafumi Yokoyama, Shimpei Yamada, Nobuyuki Doichi, Eiji Kato
}

Department of Paediatrics, Fukuiken Saiseikai Hospital, Fukui, Fukui, Japan

\section{Correspondence to} Dr Tadafumi Yokoyama, yokoyamaped@me.com
To cite: Yokoyama $T$, Yamada S, Doichi N, et al. BMJ Case Rep Published online: [please include Day Month Year] doi:10.1136/ bcr-2013-008644

\section{DESCRIPTION}

A previously healthy 2-year-old boy presented to our hospital with seizure. He had fever, diarrhoea and vomiting for 2 days before admission. His seizure continued for 2 min and was accompanied by loss of consciousness and tonic seizure. His seizure spontaneously stopped and he fully recovered. He did not have Kernig's sign or neck stiffness. Blood test and cerebrospinal fluid (CSF) analysis were normal. We made a diagnosis of simple febrile seizure.

However, $20 \mathrm{~h}$ after admission, $2 \mathrm{~min}$ of tonic seizure recurred when he was crying. At the same time, rotavirus (RV) antigen was detected in his stool.
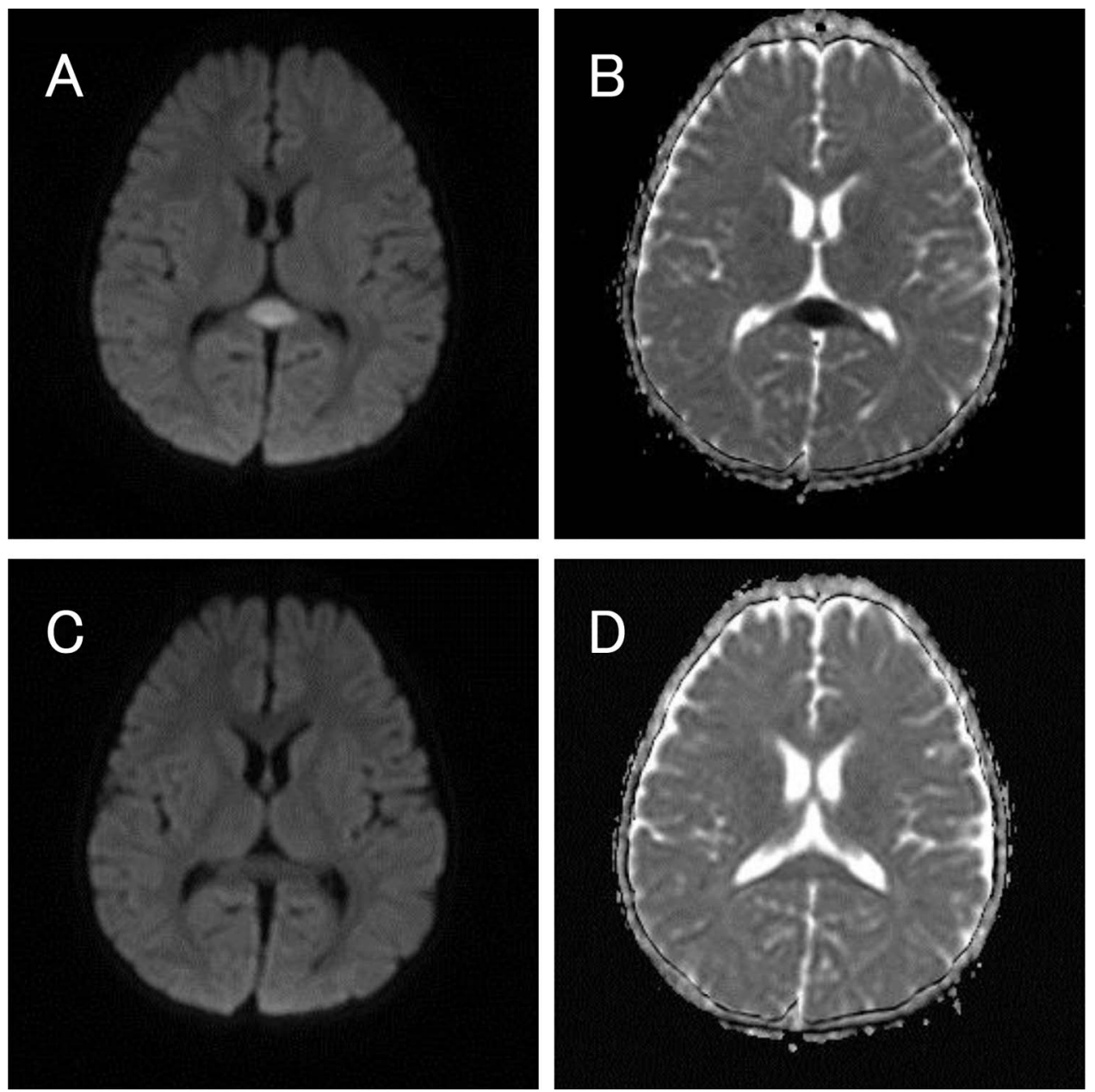

Figure 1 (A) Diffusion-weighted MRI of the brain was performed on day 3 after onset of illness showed an intensified signal in the splenium of the corpus callosum. (B) Apparent diffusion coefficient (ADC) mapping (day 3) showed decreased ADC values at the abnormality. (C) Diffusion-weighted MRI (day 9) and (D) ADC mapping (day 9) revealed complete disappearance of the original lesion.

These were some atypical findings which were different from typical simple febrile seizure that not tonic-clonic seizures but tonic seizure, occurrence of the seizure 2 days after the onset of the illness, and occurrence of the second seizure $20 \mathrm{~h}$ after the first seizure. So, he was diagnosed as possibly having encephalitis and we performed neuroimaging evaluation.

Diffusion-weighted MRI of the brain showed an intensified signal in the splenium of the corpus callosum (figure 1A). Apparent diffusion coefficient (ADC) mapping showed decreased ADC values at the abnormality (figure $1 \mathrm{~B}$ ).

We confirmed a diagnosis of RV infectionassociated clinically mild encephalopathy with a 
reversible splenial (MERS) lesion. ${ }^{1} \mathrm{He}$ was treated with oral phenobarbital and seizure did not recur. EEG performed on day 5 was normal. A follow-up brain MRI revealed completely normal findings (figure $1 \mathrm{C}, \mathrm{D}$ ) and phenobarbital was discontinued on day 9.

Tada et $a l^{1}$ identified MERS as a new type of acute encephalopathy which was characterised by transient splenial lesions with high-signal intensity in diffusion-weighted MRI, a mild course and a good outcome in 2004. MERS has been reported in encephalitis or encephalopathy induced by not only RV, but also influenza virus, adenovirus and mumps virus. ${ }^{1}$ Although MERS usually transiently recovers, MERS with RV infection should be paid attention to because of progression to cerebellitis. ${ }^{1}$ There have been some reports of hypotheses about RV-associated MERS. ${ }^{2-4}$ Some reports suggested that $\mathrm{RV}$-associated MERS was caused by direct viral invasion of the central nervous system. ${ }^{2}$ However, the other reports denied this hypothesis. ${ }^{3}$ Moreover, MERS could occur by other viruses. So, it is natural to conclude that the pathogenic mechanism of MERS is not RV-specific. In our case, RV was not detected in CSF by nested-reverse transcription PCR.

On the other hand, it has been proposed that MERS may be caused by intramyelinic axonal oedema (related from hyponatraemia) or local inflammatory cell infiltration (elevation of inflammatory cytokines such as interleukin-6 (IL-6)). ${ }^{4}$

However, hyponatraemia and elevation of IL- 6 levels in the CSF are not always found in MERS.

Taken together, the mechanisms of RV-associated MERS remain unclear.
Contributors SY and ND made substantial contributions to conception and design, acquisition of data, and analysis and interpretation of data. EK participated in revising the article critically for important intellectual content and final approval of the version to be published.

Competing interests None.

Patient consent Obtained.

Provenance and peer review Not commissioned; externally peer reviewed.

\section{REFERENCES}

1 Tada H, Takanashi J, Barkovich AJ, et al. Clinically mild encephalitis/encephalopathy with a reversible splenial lesion. Neurology 2004;63:1854-8.

2 Lynch $M$, Lee $B$, Azimi $P$, et al. Rotavirus and central nervous system symptoms: cause or contaminant? Case reports and review. Clin Infect Dis 2001;33:932-8.

3 Fuchigami T, Goto K, Hasegawa M, et al. A 4-year-old girl with clinically mild encephalopathy with a reversible splenial lesion associated with rotavirus infection. J Infect Chemother 2013;19:149-53.

4 Takanashi J, Tada H, Maeda M, et al. Encephalopathy with a reversible splenial lesion is associated with hyponatremia. Brain Dev 2009;31:521-8.

5 Subcommittee on Febrile Seizures. Febrile seizures: guideline for neurodiagnostic evaluation of the child with a simple febrile seizure. Pediatrics 2011;127:389-94.

6 Adams SM, Knowles PD. Evaluation of a first seizure. Am Fam Physician 2007;75:1342-7.

\section{Learning points}

- Neuroimaging should not be performed in the routine evaluation of the children with simple febrile seizures and the work-up of children with complex febrile seizures needs to be individualised. ${ }^{5} 6$

- When the patient with retrovirus gastroenteritis has 'atypical' febrile seizure, it is important to observe the patient carefully and think a possibility of encephalitis including mild encephalopathy with a reversible splenial lesion.

Copyright 2013 BMJ Publishing Group. All rights reserved. For permission to reuse any of this content visit http://group.bmj.com/group/rights-licensing/permissions.

BMJ Case Report Fellows may re-use this article for personal use and teaching without any further permission.

Become a Fellow of BMJ Case Reports today and you can:

- Submit as many cases as you like

- Enjoy fast sympathetic peer review and rapid publication of accepted articles

- Access all the published articles

- Re-use any of the published material for personal use and teaching without further permission

For information on Institutional Fellowships contact consortiasales@bmjgroup.com

Visit casereports.bmj.com for more articles like this and to become a Fellow 